\title{
Hyperplasia-adenoma sequence in pituitary tumorigenesis related to aryl hydrocarbon receptor interacting protein gene mutation
}

\author{
Chiara Villa ${ }^{1,2}$, Maria Stefania Lagonigro ${ }^{2}$, Flavia Magri ${ }^{2}$, Maria Koziak ${ }^{3}$, \\ Marie-Lise Jaffrain-Rea ${ }^{4,5}$, Raja Brauner ${ }^{\prime}$, Jerome Bouligand ${ }^{7}$, \\ Marie Pierre Junier ${ }^{1}$, Federico Di Rocco ${ }^{8}$, Christian Sainte-Rose, \\ Albert Beckers ${ }^{9}$, François Xavier Roux ${ }^{3}$, Adrian F Daly $^{9}$ and Luca Chiovato ${ }^{2}$ \\ ${ }^{1}$ Unit of Neuropathology, INSERM U984 Laboratory of Glial Plasticity, Centre Hospitalier Sainte Anne, University of Paris Descartes, \\ 1 Rue Cabanis, 75014 Paris, France \\ ${ }^{2}$ Unit of Internal Medicine and Endocrinology, Fondazione Salvatore Maugeri IRCCS, ISPESL Laboratory for Endocrine Disruptors, \\ Department of Endocrinology, University of Pavia, Pavia, Italy \\ ${ }^{3}$ Unit of Neurosurgery, Centre Hospitalier Sainte Anne, University of Paris Descartes, Paris, France \\ ${ }^{4}$ Department of Experimental Medicine, University of L'Aquila, L'Aquila, Italy \\ ${ }^{5}$ Neuromed Institute, Pozzilli, Italy \\ ${ }^{6}$ Unit of Pediatric Endocrinology, Hôpital Bicêtre, University of Paris Descartes and AP-HP, Paris, France \\ ${ }^{7}$ University of Paris-Sud, Hôpital Bicêtre, INSERM UMR-S693, Paris, France \\ ${ }^{8}$ Department of Pediatric Neurosurgery, Hôpital Necker Enfants-Malades, University of Paris Descartes, Paris, France \\ ${ }^{9}$ Department of Endocrinology, Centre Hospitalier Universitaire de Liège, University of Liège, Liège, Belgium \\ (Correspondence should be addressed to A Beckers, Department of Endocrinology, $\mathrm{CHU}$ de Liège; \\ Email: albert.beckers@chu.ulg.ac.be; C Villa at Unit of Neuropathology, INSERM U984 Laboratory of Glial Plasticity; \\ Email: chiaravilla@ hotmail.it)
}

\begin{abstract}
Mutations of the aryl hydrocarbon receptor interacting protein $(A I P)$ gene are associated with pituitary adenomas that usually occur as familial isolated pituitary adenomas (FIPA). Detailed pathological and tumor genetic data on AIP mutation-related pituitary adenomas are not sufficient. Non-identical twin females presented as adolescents to the emergency department with severe progressive headache caused by large pituitary macroadenomas require emergency neurosurgery; one patient had incipient pituitary apoplexy. Post-surgically, the patients were found to have silent somatotrope adenomas on pathological examination. Furthermore, the light microscopic, immunohistochemical, and electron microscopic studies demonstrated tumors of virtually identical characteristics. The adenomas were accompanied by multiple areas of pituitary hyperplasia, which stained positively for $\mathrm{GH}$, indicating somatotrope hyperplasia. Genetic analyses of the FIPA kindred revealed a novel E216X mutation of the AIP gene, which was present in both the affected patients and the unaffected father. Molecular analysis of surgical specimens revealed loss of heterozygosity $(\mathrm{LOH})$ in the adenoma but showed that LOH was not present in the hyperplastic pituitary tissue from either patient. AIP immunostaining confirmed normal staining in the hyperplastic tissue and decreased staining in the adenoma in the tumors from both patients. These results demonstrate that patients with AIP germline mutation can present with silent somatotrope pituitary adenomas. The finding of somatotrope hyperplasia unaccompanied by AIP LOH suggests that $\mathrm{LOH}$ at the AIP locus might be a late event in a potential progression from hyperplastic to adenomatous tissue.
\end{abstract}

Endocrine-Related Cancer (2011) 18 347-356

\section{Introduction}

Pituitary adenomas are the most common tumors arising in the pituitary gland, with a prevalence of about $17 \%$ in unselected autopsy and radiological series (Ezzat et al. 2004). Clinically relevant anterior pituitary tumors have prevalence in the general population of $\sim 1: 1064$ to 1:1288 (Daly et al. 2006, Fernandez et al. 2010). Pituitary adenomas carry a 
heavy clinical burden due to the effects of hormonal hypersecretion or deficiency, damage to important local structures, and the necessity for invasive surgery and/or chronic medical therapy. Multiple molecular genetic alterations related to pituitary adenomas have been identified, mainly as somatic mutations in sporadic tumors (Asa \& Ezzat 2009). Familial pituitary adenomas are infrequent (5\% of the total) but are of clinical interest due to the possibility for earlier diagnosis of tumors via screening for germline genetic mutations (Daly et al. 2009a).

Established syndromes that are associated with familial pituitary adenomas include multiple endocrine neoplasia type 1 (MEN1), due to MEN1 gene mutations, and acromegaly occurring as a component of the Carney complex (CNC), associated with PRKARIA gene mutations (Bertherat et al. 2009, Daly et al. 2009b). Inactivating mutations of the CDKN1B gene cause MEN4, a rare condition potentially associated with inherited pituitary tumor risk (Pellegata et al. 2006, Agarwal et al. 2009). Pituitary adenomas also occur in a familial setting in the absence of MEN1 and CNC, in familial isolated pituitary adenoma (FIPA) kindreds (Beckers \& Daly 2007). Vierimaa et al. (2006) reported that inactivating mutations of the aryl hydrocarbon receptor interacting protein gene $(A I P)$ occurred in families with pituitary adenomas. AIP mutations account for $15 \%$ of FIPA families (Daly et al. 2007) and may be found in 4-5\% of patients with acromegaly (Cazabat et al. 2009). AIP mutation-related pituitary adenomas are typically seen in young patients, are large and commonly invasive at diagnosis, and are usually somatotropinomas or prolactinomas, although rare cases of non-secreting adenomas and other subtypes also occur (Daly et al. 2010). AIP may act as a tumor suppressor gene, as loss of heterozygosity $(\mathrm{LOH})$ occurs in pituitary tumor tissue (Vierimaa et al. 2006), although AIP immunostaining is abolished in only a minority of tumors from AIP mutation-bearing patients (Jaffrain-Rea et al. 2009). AIP overexpression in vitro decreases cell proliferation (Leontiou et al. 2008), AIP gene silencing results in cell proliferation (Heliovaara et al. 2009), and recent results from an Aip knockout mouse match the human phenotype (Raitila et al. 2010).

We describe the detailed morphological and pathological features of pituitary tumors in a new FIPA family with a novel AIP mutation, paying particular attention to somatic genetic status of $A I P$ in surgical samples that revealed features of pituitary hyperplasia, which is a novel pathological topic that has not previously been well described in this genetic background.
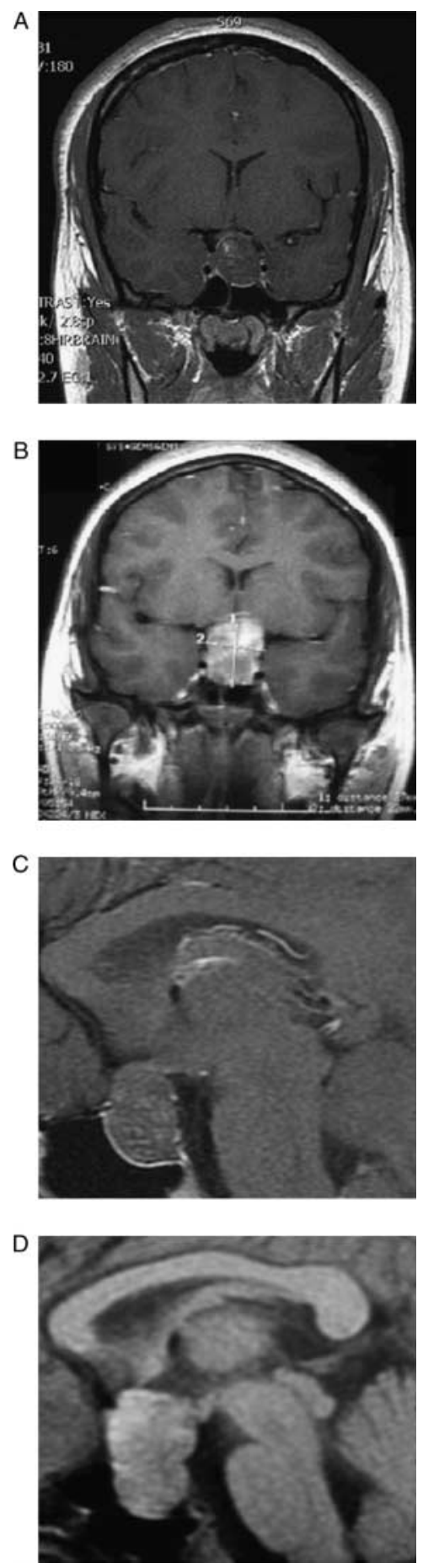

Figure 1 Radiological imaging studies. Panels $\mathrm{A}$ and $\mathrm{C}$, contrast enhanced MRI of the brain in patient 1 showing a pituitary macroadenoma of $25 \times 20 \mathrm{~mm}$, compressing the optic chiasm with an area of hemorrhage or necrosis. Panels $B$ and $\mathrm{D}$, contrast-enhanced brain MRI of patient 2 with a pituitary macroadenoma of $32 \times 35 \mathrm{~mm}$ with compression of the optic chiasm and heterogeneous uptake of contrast agent; this tumor was found to be hemorrhagic on emergency surgery. 


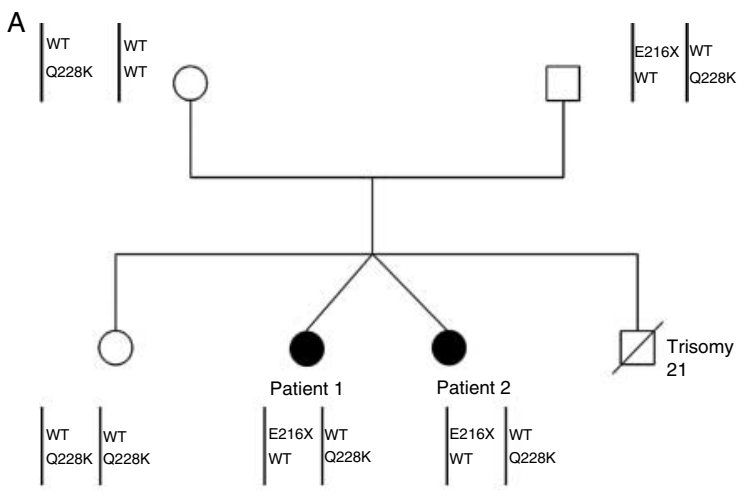

B
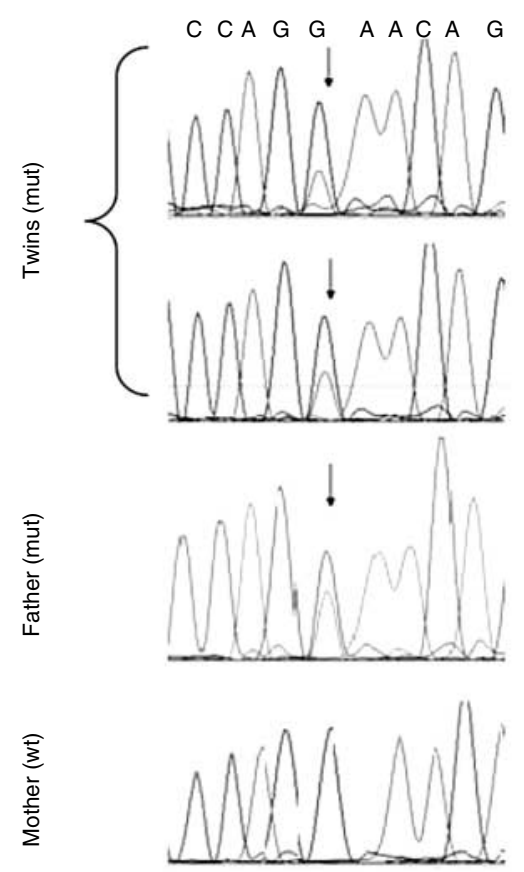


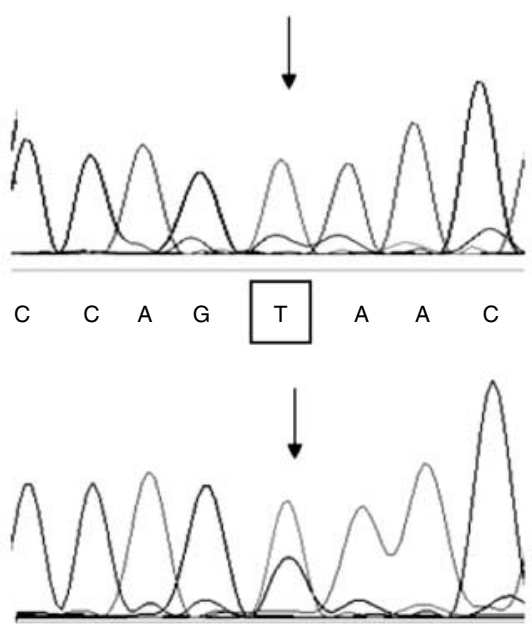

\section{Methods}

\section{Patients and family history}

The index case was a 17 -year-old female, who was first seen at our institution in December 2008. She had a 4-week history of headache that had rapidly worsened in severity over the preceding $48 \mathrm{~h}$, the pain being resistant to opiate analgesia. There was no grossly diminished visual acuity (perimetry was not performed). Minor galactorrhea was present bilaterally, menses were regular, and no other clinical evidence of endocrine dysfunction was apparent. Medical history was notable only for asthma. At presentation, her height and weight were $166 \mathrm{~cm}$ and $75 \mathrm{~kg}$ respectively.

Magnetic resonance imaging (MRI) of the brain revealed a pituitary macroadenoma measuring $25 \times 20 \mathrm{~mm}$ that compressed the optic chiasm and had evidence of necrosis/hemorrhage (Fig. 1A and C). Pituitary hormone levels were within the normal range. In view of the severe presentation, the patient underwent emergency tumor resection through a direct paraseptal transsphenoidal approach; the tumor was fully excised. After surgery, she developed transitory diabetes insipidus and secondary adrenal deficiency. In June 2009, a follow-up MRI showed no evidence of recurrence.

During investigation of patient 1 , family history revealed that in October 2003 her non-identical twin sister presented with a pituitary tumor elsewhere, at the age of 12 years. The clinical presentation was a rapidly progressive headache over the previous 3 weeks associated with vomiting. There was a sudden loss in visual acuity immediately before presentation and papilledema was present on examination. The patient's height and weight were $162 \mathrm{~cm}$ and $62 \mathrm{~kg}$ respectively; she also suffered from bronchial asthma. No features of acromegaly or other signs/symptoms suggestive of an endocrine abnormality were present. On MRI she had a large pituitary adenoma measuring $32 \times 35 \mathrm{~mm}$ with suprasellar extension, compression of the optic chiasm and heterogeneous uptake of the contrast agent (Fig. 1B and D). Preoperative hormonal evaluation was not performed. Owing to a high suspicion of pituitary

Figure 2 Genealogy and AIP sequencing information. Panel A, genealogic tree of the immediate family of the affected patients indicating AIP genotype and polymorphism data. Panel B, the sequences of AIP demonstrating germline E216X mutations in the two affected patients and in the unaffected father and the wild-type sequence in the mother are shown. Panel $\mathrm{C}$, loss of heterozygosity (LOH) at the AIP locus in samples of tumor DNA from the pituitary adenomas of both affected sisters; DNA extracted from zones of hyperplasia or residual adenohypophysis did not show similar LOH. 
apoplexy, the patient underwent an emergency sub-frontal craniotomy that demonstrated a giant ( $>40 \mathrm{~mm}$ maximum diameter) hemorrhagic pituitary adenoma. The patient developed hypopituitarism and permanent diabetes insipidus post-operatively. Normal visual acuity was re-established. Follow-up MRIs in 2006 and 2009 showed no recurrence. The patient's height at age 17 was $170 \mathrm{~cm}$ and she weighed $92 \mathrm{~kg}$.

The genealogy is shown in Fig. 2A. The patients' mother was 56 years old (weight: $79 \mathrm{~kg}$, height: $160 \mathrm{~cm}$ ) from Morocco. She had no medical history of note. The father was aged 48 years (weight: $90 \mathrm{~kg}$, height: $189 \mathrm{~cm}$ ) and from Algeria; he had no relevant medical history and normal basal pituitary hormone levels. The older sister of the two patients was aged 20 years, suffered from bronchial asthma, and had normal pituitary hormone studies. The mother, father, and sister declined MRI. A younger brother was born in 1998 with Down syndrome and a severe congenital cardiac abnormality and died at the age of 1 year due to bronchiolitis and heart failure. Other members of the kindred predominantly lived in North Africa and were unavailable for or declined medical assessments. The patients' father had 13 siblings; all were well and reported no endocrine/neurologic/oncologic diseases. The paternal grandparents died due to heart failure and smoking-related lung cancer. The maternal grandmother and 12 siblings of patients' mother were alive and well; the maternal grandfather had died of causes unrelated to endocrine or oncologic pathologies.

\section{Genetic studies}

Based on the familial presentation of pituitary adenomas, the patients and first-degree relatives underwent screening for germline mutations of the $M E N 1$ gene. As there was no clinical evidence or features of CNC, PRKARlA screening was not warranted. The patients met the criteria for FIPA and underwent germline screening for an AIP mutation. All individuals and their guardians provided written informed consent for clinical and genetic investigations, and the study was performed according to the Declaration of Helsinki.

For AIP and MENI studies, genomic DNA was extracted from peripheral blood using the QIAamp DNA Blood Midi kit and from paraffin-embedded surgical pituitary specimens using the QIAamp DNA mini kit (Qiagen). Isolated DNA was submitted to spectrophotometric quantization and then to quality assessment using $\beta$-actin PCR. The PCR/sequencing primers and conditions for $A I P$ analysis were as described previously (Vierimaa et al. 2006). The PCR products were visualized on agarose gels using ethidium bromide and were then purified by QIAquick PCR purification kit (Qiagen).
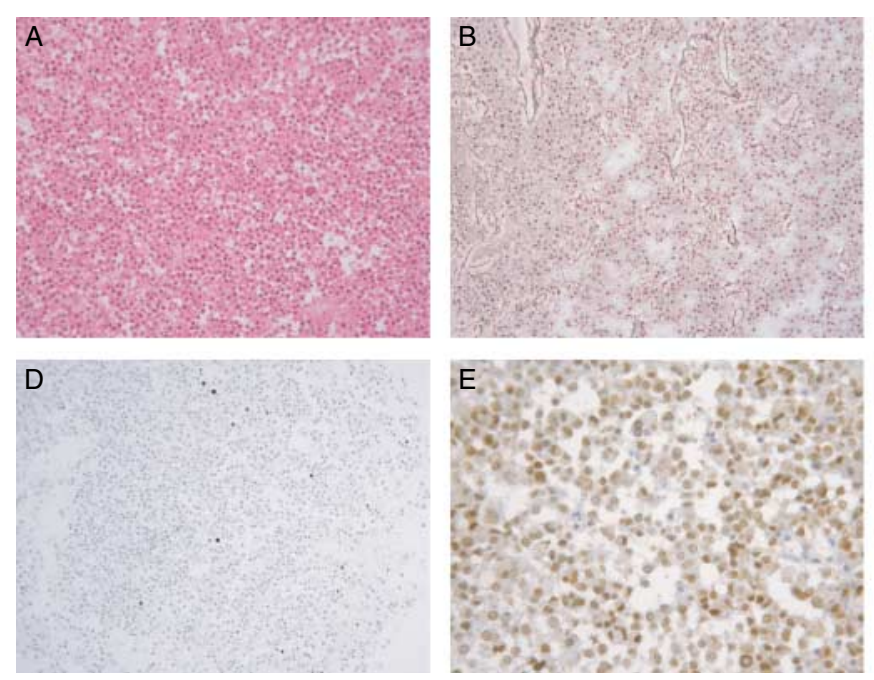
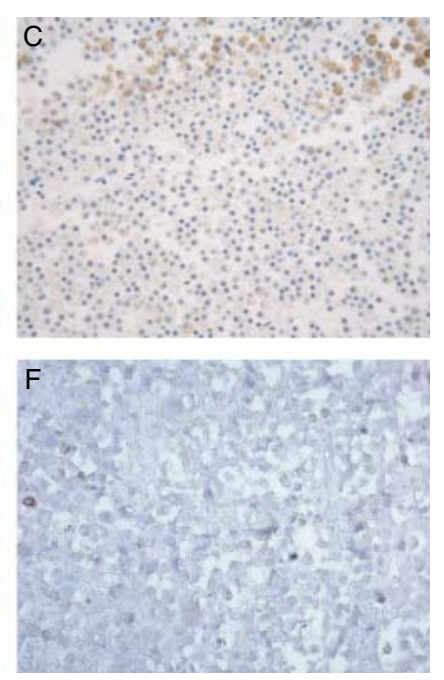

Figure 3 Histological characterization of pituitary adenoma of patient 1. Panel A, hematoxylin- and eosin-stained fragments from pituitary adenoma show a solid architecture pattern of predominantly small, round cells with acidophil cytoplasm $(\times 20$ magnification). Panel B, on reticulin stain, adenoma exhibits a complete loss of the normal reticulin pattern ( $\times 20$ magnification). Panel C, on GH immunostain, scattered cells are immunoreactive for GH with a cytoplasmic pattern $(\times 20$ magnification). Panel D, on MIB1/Ki67 immunostain, nuclear expression is observed in scattered cells ( $\times 10$ magnification). The proliferation index was globally evaluated at $3 \%$ on the tumor samples. Panel E, Pit-1 immunostain shows homogeneous nuclear expression in pituitary adenoma cells (negative controls: endothelial and/or inflammatory cells) ( $\times 40$ magnification). Panel F, AIP immunostain where present is cytoplasmic and weak in pituitary adenoma cells ( $\times 40$ magnification). Only scattered cells were positive for AIP. 
Direct sequencing of the AIP gene was performed using Big Dye 1.1 Terminator on an ABI PRISM 310 Genetic Analyzer (Applied Biosystems, Foster City, CA, USA). Reference AIP sequences were downloaded from the EMBL nucleotide database (accession number ENST00000279146) and matched with the NCBI database (GenBank Accession number NM_003977.2).MEN1 gene sequencing was performed with the BigDye Terminator on an ABI377 DNA sequencer (Applied Biosystems). Chromatograms were analyzed using the Lasergene Navigator Software (GATC, Koustauz, Germany) and blasted against the published MEN1 genomic sequence (GenBank accession number U93237).

\section{Histological studies}

Pituitary surgical samples were fixed in formalin and embedded in paraffin. Sections $5 \mu \mathrm{m}$ thick were stained with hematoxylin-eosin, periodic acid-Schiff, and reticulin for light microscopy. Immunostains for all anterior pituitary hormones, CAM5.2, MIB1/Ki67, chromogranin A, Pit-1, and AIP, were performed as described elsewhere (Villa et al. 2008, Jaffrain-Rea et al. 2009).

An ultrastructural study was performed as described previously (Villa et al. 2008), which was limited by the formalin-fixing and paraffin-embedding protocol to the evaluation of secretory granule diameter and cytoplasmic distribution (for detailed discussion of ultrastructural findings in $A I P$-mutated pituitary adenomas, see Leontiou et al. (2008)). Before tissue microdissection was performed, normal, adenomatous, and hyperplastic pituitary tissues were identified using reticulin staining. Multiple well-defined sites from pathological specimens were identified in this way for microdissection: normal pituitary $(n=3)$, adenoma $(n=5)$ and hyperplastic tissue $(n=4)$. An initial $5 \mu \mathrm{m}$-thick tissue section was stained with reticulin for light microscopic examination; subsequently, ten $7 \mu \mathrm{m}$-thick serial sections were cut for manual tissue microdissection. An eleventh $5 \mu \mathrm{m}$-thick section was stained with reticulin in order to control for changes in the distribution of pathological and normal pituitary tissue areas. Manual scraping of different pituitary tissue areas in all ten $7 \mu \mathrm{m}$-thick serial tissue sections was performed using a fine needle tip. The resulting paraffin-embedded material was collected for DNA extraction (Kristiansen 2010).

\section{Results}

\section{Genetic analysis}

Both affected patients had a novel heterozygous E216X AIP mutation in exon 5 (Fig. 2B). The clinically unaffected father was a carrier of this mutation, whereas the mother and older sister were of wild-type. Both patients and both parents were heterozygotic for the previously described Q228K
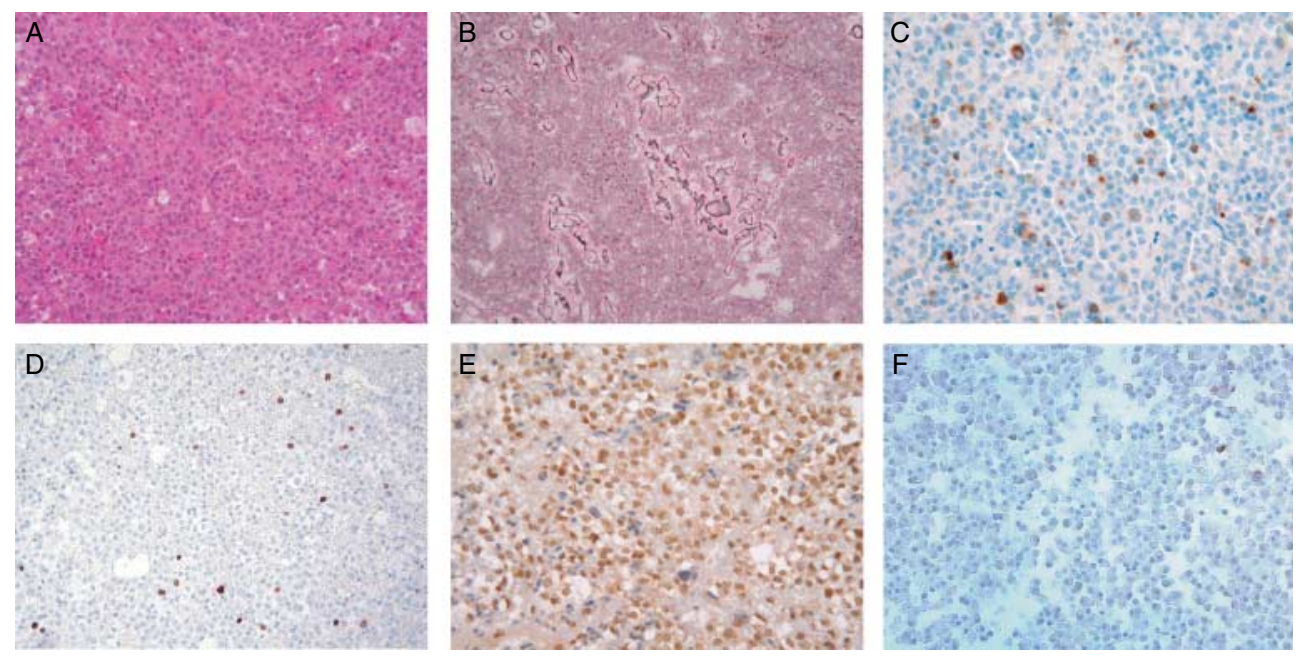

Figure 4 Histological characterization of pituitary adenoma of patient 2. Panel A, hematoxylin and eosin stain fragments from pituitary adenoma show a solid architecture pattern of predominantly small round cells with acidophil cytoplasm ( $\times 20$ magnification). Panel B, on reticulin stain, adenoma revealed total breakdown of reticulin pattern ( $\times 20$ magnification). Panel $\mathrm{C}$, the adenoma demonstrated scattered cells immunoreactive for $\mathrm{GH}$ with a cytoplasmic or Golgi-like pattern ( $\times 40$ magnification). Panel D, on MIB1/Ki67 immunostain, nuclear expression is observed in some cells as well in one mitosis ( $\times 20$ magnification). The proliferation index was globally evaluated at $5 \%$ on the tumor samples. Panel E, Pit-1 immunostain shows homogeneous nuclear expression in pituitary adenoma cells (negative controls: endothelial and/or inflammatory cells) ( $\times 40$ magnification). Panel F, AIP immunostain where present is cytoplasmic and weak in pituitary adenoma cells ( $\times 40$ magnification). Only scattered cells were positive for AIP. 

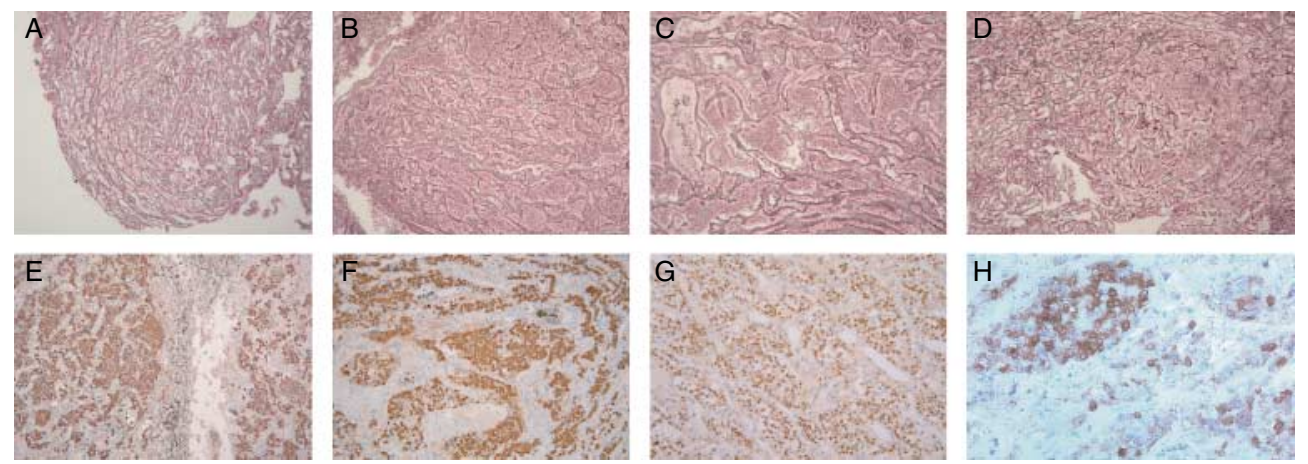

Figure 5 Histological characterization of pituitary hyperplasia of patient 1. Panel A, reticulin stain of residual normal adenohypophysis ( $\times 10$ magnification). Panels $B$ and $C$, in areas of hyperplasia, the reticulin fiber network is preserved but the acini are expanded compared with normal adenohypophysis ( $\times 10$ magnification). Panel $D$, transformation zone from hyperplasia to adenoma ( $\times 10$ magnification). From the left side to the right side of this panel, the reticulin fiber network shows a gradual disruption. Panels $\mathrm{E}$ and $\mathrm{F}$, diffuse, cytoplasmic $\mathrm{GH}$ immunoreactivity observed in hyperplastic acini ( $\times 10$ magnification). Panel G, homogeneous nuclear expression of Pit- 1 was observed in hyperplastic acini ( $\times 20$ magnification). Panel $\mathrm{H}$, AIP immunostain is strong and cytoplasmic in hyperplastic acini ( $\times 40$ magnification).

(rs641081) polymorphism; the older sister was homozygotic for this polymorphism. Sequencing of AIP in tumor tissue revealed $\mathrm{LOH}$ in adenoma samples from both patients (Fig. 2C). In contrast, LOH for the AIP gene was found in neither the hyperplastic nor the normal pituitary DNA samples.

MEN1 gene sequencing demonstrated wild-type sequences in all patients and subjects apart from the mother who had a previously described exon 10 polymorphism/missense mutation A541T (Bazzi et al. 2008). No clinical evidence consistent with a diagnosis of MEN1 was found in the mother.

\section{Histopathology}

Histopathological findings from the pituitary tumors of both patients were very similar. Both had tissue fragments with a solid architectural pattern of predominantly small round cells with acidophil cytoplasm (Figs 3A, B and 4A, B). There was evidence of infarction, hemorrhage (patient 1), and ischemia (both patients).

Reticulin staining revealed total breakdown of the reticulin pattern in adenomatous tissue (Figs 3B and 4B), although expanded acini with a well-developed reticulin fiber network were observed in areas of pituitary hyperplasia (Figs 5B, C and 6B, C). Regions of normal pituitary as well as zones of transition from hyperplasia to adenoma were also observed (Figs 5A, $\mathrm{D}$ and 6A, D).

Immunohistochemistry of both tumors showed scattered GH and rare prolactin-positive cells (Figs 3C and 4C). Areas of pituitary hyperplasia showed a diffuse cytoplasmic GH immunoreactivity (Figs 5E, $\mathrm{F}$ and $6 \mathrm{E})$. All adenoma fragments and hyperplastic areas were immunoreactive for Pit-1 (Figs 3E, 4E, 5G and $6 \mathrm{G})$. In the tumor of patient 1 , the Ki-67/MIB1 proliferation index was $3 \%$, with mitotic activity $<1$ mitosis per 10 high-power fields (HPF), while in patient 2, the proliferation index in the adenoma was $5 \%$ with seven mitoses per 10 HPF (Figs 3D and 4D). Rare cells in hyperplastic areas were positive for MIB1/Ki67, whereas in residual normal pituitary, only exceptional cells appeared immunoreactive (Fig. 6F). Rarely, tumor cells expressed CAM5.2 with a perinuclear 'dot-like' pattern. AIP staining was weak and scattered in both adenomas and localized to the cytoplasm. In contrast, AIP staining was strongly positive in the hyperplastic areas (Figs 3F, 4F, 5H and $6 \mathrm{H})$ and in normal pituitary.

The ultrastructural features were suggestive of sparsely granulated adenomas. The diameter of the sparse, spherical, electron-dense, cytoplasmic secretory granules ranged from 110 to $290 \mathrm{~nm}$ (mean: $180 \mathrm{~nm}$ ) in patient 1 and from 120 to $280 \mathrm{~nm}$ (mean: $200 \mathrm{~nm}$ ) in patient 2 . Tumor from patient 2 also demonstrated some densely granulated cells, with granules of 190-480 nm (mean: $335 \mathrm{~nm}$ ) in diameter. According to the definition of silent pituitary adenoma proposed by the AFIP and WHO classification of pituitary tumors, the pathological diagnosis in both cases was consistent with a silent somatotrope adenoma (Asa 2008, Osamura et al. 2008).

\section{Discussion}

In this study, we describe a new FIPA kindred in which non-identical female twins presented in adolescence with pituitary macroadenomas in association with a novel E216X mutation of AIP. These patients highlight 

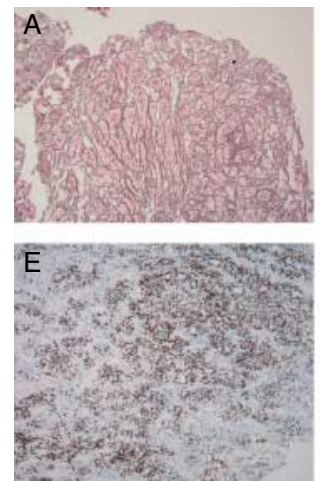
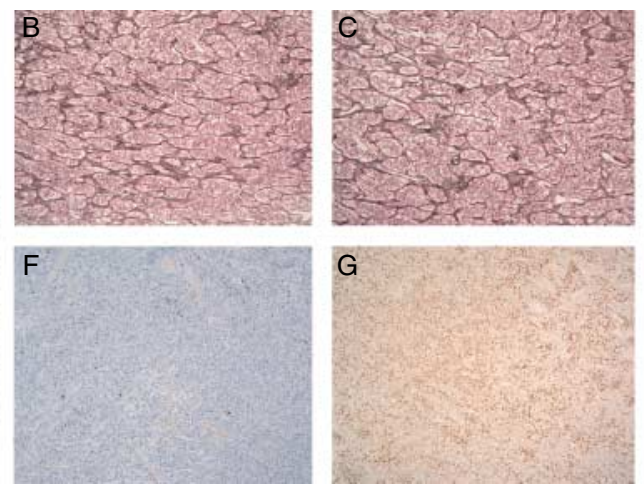
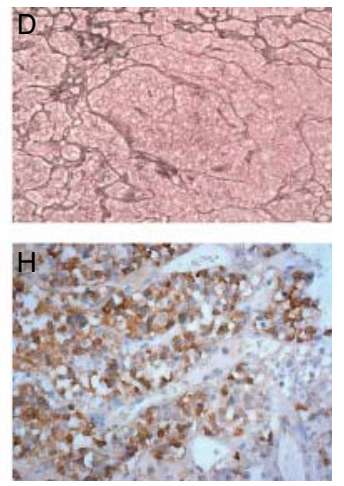

Figure 6 Histological characterization of pituitary hyperplasia of patient 2. Panel A, reticulin stain of residual normal adenohypophysis ( $\times 10$ magnification). Panels $B$ and $C$, in areas of hyperplasia, the reticulin fiber network is preserved but the acini are expanded compared with normal adenohypophysis ( $\times 10$ magnification). Panel $D$, transformation zone from hyperplasia to adenoma ( $\times 10$ magnification). From the left to the right side of Panel $D$, the reticulin fiber network shows a gradual disruption. Panel E, a diffuse, cytoplasmic GH immunoreactivity is observed in hyperplastic acini ( $\times 10$ magnification). Panel F, on MIB1/Ki67 immunostain, nuclear expression is observed in rare cells in a hyperplastic area ( $\times 10$ magnification). Panel $G$, homogeneous nuclear expression of Pit-1 was observed in hyperplastic acini ( $\times 10$ magnification). Panel H, AIP immunostain is strong and cytoplasmic in hyperplastic acini ( $\times 40$ magnification).

the current understanding of $A I P$ mutation-associated pituitary adenomas as large, aggressive tumors in young patients (Daly et al. 2010), which manifested in these kindred as emergency presentations in both and as pituitary apoplexy at the age of 12 years in one twin. The role of $A I P$ in predisposing to pituitary adenomas was first described by Aaltonen's group in 2006 (Vierimaa et al. 2006). Such patients are predisposed preferentially to somatotropinomas and prolactinomas, although non-secreting adenomas, Cushing disease and thyrotropinomas also occur infrequently. In these FIPA kindred, the diagnosis in both twins was consistent with a silent somatotrope pituitary macroadenoma. This diagnosis is supported by the lack of growth disorders and other clinical symptoms or signs attributable to somatotrope hypersecretion. Owing to this lack of suggestive symptoms or signs in advance of emergency presentation, the standard hormonal workup (including dynamic pituitary function tests) was not available before surgery. For this reason, although the current patients were unlikely to have the very elevated $\mathrm{GH}$ levels and concomitant symptoms typical of $A I P$-mutation-related somatotropinomas (Daly et al. 2010), more subtle abnormalities in the somatotrope axis such as those commonly seen in CNC cannot be ruled out (Boikos \& Stratakis 2006). The pathological designation is suggested by the presence of scattered GH-positive cells (Figs 3C and 4C) and immunoreactivity for Pit-1 (Figs 3E and 4E). As only exceptional cells were immunoreactive for prolactin in both adenomas, this observation was considered insufficient to classify these adenomas as somatomammotrope (Asa 2008, Osamura et al. 2008).
The most important finding on histological study of these two tumors suggests that pituitary hyperplasia may accompany pituitary tumor formation against a background of an AIP mutation. Histopathological diagnosis of somatotrope pituitary hyperplasia may be difficult due to the high concentration of somatotrope cells in the lateral wings of the adenohypophysis and the interpretation of expanded acini on reticulin staining can be prone to subjectivity. In both tumors, reticulin staining demonstrated clearly enlarged acini in the hyperplastic regions compared with normal adenohypophysis (Figs 5A-C and 6A-C). Areas of transformation from hyperplasia to adenoma were seen (Figs 5D and 6D), which are rarely noted in surgical samples in the absence of hyperplasia. Although MIB1/Ki67 immunostaining is not recognized as a criterion to confirm pituitary hyperplasia, the proliferation index clearly increased from low in residual normal pituitary and hyperplasia to high in adenoma (Figs 6F, 3D and 4D). Immunohistochemistry demonstrated that the hyperplastic regions in both tumors stained positively for $\mathrm{GH}$, indicating their derivation from somatotropes (Figs 5E, F and 6E). Hyperplastic and adenomatous areas stained uniformly for Pit-1, supporting a common developmental lineage (Figs 5G and 6G). Importantly, these zones of hyperplasia did not display LOH for the E216X mutation, unlike the $\mathrm{LOH}$ observed in adenomatous tissue. $\mathrm{LOH}$ is an established feature in pituitary tumors associated with germline AIP mutations (Vierimaa et al. 2006, Daly et al. 2007, Leontiou et al. 2008). These results were also confirmed by AIP immunostains (Figs 3F, 4F, 5H and $6 \mathrm{H})$. Indeed, in hyperplastic areas in both tumors, 
the cells stained strongly positive for AIP, although in both adenomas, the immunoreactivity was very weak. Staining was not completely absent as the E216X mutation affects exon 5 (i.e. the epitope is preserved) and low levels of mutated protein are likely to be expressed as have been seen for multiple other AIP mutations (Jaffrain-Rea et al. 2009).

Hyperplasia of the type seen in this study is not a feature of MEN1-related pituitary adenomas, the other frequent known genetic cause of familial pituitary adenomas. As shown by Trouillas et al. (2008) in a large case-control study, somatotrope hyperplasia was found in only 3/77 MEN1 pituitary tissues, with 2/3 being caused by GHRH hypersecretion from a pancreatic tumor. Pituitary hyperplasia is, however, characteristic of patients with $\mathrm{CNC}$ and acromegaly (Pack et al. 2000), although the tumor multicentricity seen in CNC has not been seen to date in the setting of AIP mutations. In contrast to the tumors in this study where the hyperplastic areas were immunoreactive for GH only, pituitary hyperplasia in CNC is characterized by $\mathrm{GH}$ and prolactin immunoreactivity (Boikos \& Stratakis 2006). McCune-Albright syndrome (MAS) is also associated with acromegaly and disorders of both GH and prolactin secretion in which diffuse somatomammotrope hyperplasia accompanying the adenoma has been described (Kovacs et al. 1984, Dumitrescu \& Collins 2008). In CNC and MAS, patients may exhibit elevations in hormone levels in the absence of an overt adenoma. However, among carriers of $A I P$ mutations, no similar disorder has been noted to date (Beckers \& Daly, personal communication), which suggests that hormonal abnormalities associated with AIP mutations are due to the adenoma itself, without a major contribution from any hyperplasia possibly present. In MEN1 and CNC, multiple pituitary tumors may be seen, which again has not been noted in the setting of AIP mutation-related pituitary adenomas (Magri et al. 2010).

In summary, we describe a hyperplasia-adenoma sequence in pituitary tumorigenesis against a background of a novel AIP germline mutation (E216X). The clinical presentation, in two non-identical twin females carrying this same AIP germline mutation, was remarkably similar with pituitary macroadenomas and acute symptom onset in young patients. The tumor genetic and pathological findings were virtually identical in both patients, who presented with unusual silent somatotrope adenomas. For the first time, pituitary hyperplasia that was not accompanied by LOH for the AIP gene has been described; this differs from $\mathrm{LOH}$ findings in the tumor tissue. Our study suggests that AIP LOH might be a late event in the pituitary tumorigenesis sequence since $\mathrm{LOH}$ was observed in the adenoma and was absent in hyperplastic regions, whereas normal AIP immunostaining was preserved in the hyperplastic regions and largely lost in the adenomatous tissue. This raises the possibility of other genetic events occurring as concomitant drivers of pituitary tumorigenesis (e.g. digenic disease), which may help explain the current low or moderate penetrance of pituitary adenomas among carriers of $A I P$ germline mutations. As pituitary hyperplasia may be a feature of other patients with $A I P$ mutations (Stratakis et al. 2010) or in patients with gigantism (Scheithauer et al. 1995), which is itself frequently associated with $A I P$ mutations, studies combining large numbers of pituitary tumors of differing AIP mutation origin could elucidate the potential role of hyperplasia in the development of pituitary adenomas in individuals with germline $A I P$ mutations.

\section{Declaration of interest}

The authors declare that there is no conflict of interest that could be perceived as prejudicing the impartiality of the research reported.

\section{Funding}

This research was supported by an academic grant from the Fonds d'Investissements de la Recherche Scientifique (FIRS) of the Centre Hospitalier Universitaire de Liège.

\section{Author contribution statement}

All authors were involved in writing the paper and had final approval of the submitted and published versions.

\section{References}

Agarwal SK, Ozawa A, Mateo CM \& Marx SJ 2009 The MEN1 gene and pituitary tumours. Hormone Research 71 (Supplement 2) 131-138. (doi:10.1159/000192450)

Asa SL 2008 Practical pituitary pathology: what does the pathologist need to know? Archives in Pathology and Laboratory Medicine 132 1231-1240.

Asa SL \& Ezzat S 2009 The pathogenesis of pituitary tumors. Annual Review of Pathology 4 97-126. (doi:10.1146/ annurev.pathol.4.110807.092259)

Bazzi W, Renon M, Vercherat C, Hamze Z, LacheretzBernigaud A, Wang H, Blanc M, Roche C, Calender A, Chayvialle JA et al. 2008 MEN1 missense mutations impair sensitization to apoptosis induced by wild-type menin in endocrine pancreatic tumor cells. Gastroenterology 135 1698.e2-1709.e2. (doi:10.1053/j. gastro.2008.07.031) 
Beckers A \& Daly AF 2007 The clinical, pathological, and genetic features of familial isolated pituitary adenomas. European Journal of Endocrinology 157 371-382. (doi:10.1530/EJE-07-0348)

Bertherat J, Horvath A, Groussin L, Grabar S, Boikos S, Cazabat L, Libe R, Rene-Corail F, Stergiopoulos S, Bourdeau I et al. 2009 Mutations in regulatory subunit type $1 \mathrm{~A}$ of cyclic adenosine $5^{\prime}$-monophosphate-dependent protein kinase (PRKAR1A): phenotype analysis in 353 patients and 80 different genotypes. Journal of Clinical Endocrinology and Metabolism 94 2085-2091. (doi:10. 1210/jc.2008-2333)

Boikos SA \& Stratakis CA 2006 Pituitary pathology in patients with Carney complex: growth-hormone producing hyperplasia or tumors and their association with other abnormalities. Pituitary 9 203-209. (doi:10.1007/ s11102-006-0265-2)

Cazabat L, Guillaud-Bataille M, Bertherat J \& Raffin-Sanson ML 2009 Mutations of the gene for the aryl hydrocarbon receptor-interacting protein in pituitary adenomas. Hormone Research 71 132-141. (doi:10.1159/000197869)

Daly AF, Rixhon M, Adam C, Dempegioti A, Tichomirowa MA \& Beckers A 2006 High prevalence of pituitary adenomas: a cross-sectional study in the province of Liege, Belgium. Journal of Clinical Endocrinology and Metabolism 91 4769-4775. (doi:10.1210/jc.2006-1668)

Daly AF, Vanbellinghen JF, Khoo SK, Jaffrain-Rea ML, Naves LA, Guitelman MA, Murat A, Emy P, GimenezRoqueplo AP, Tamburrano G et al. 2007 Aryl hydrocarbon receptor-interacting protein gene mutations in familial isolated pituitary adenomas: analysis in 73 families. Journal of Clinical Endocrinology and Metabolism 92 1891-1896. (doi:10.1210/jc.2006-2513)

Daly AF, Tichomirowa MA \& Beckers A $2009 a$ Update on familial pituitary tumors: from multiple endocrine neoplasia type 1 to familial isolated pituitary adenoma. Hormone Research 71 (Supplement 1) 105-111. (doi:10. 1159/000178050)

Daly AF, Tichomirowa MA \& Beckers A $2009 b$ Genetic, molecular and clinical features of familial isolated pituitary adenomas. Hormone Research 71 (Supplement 2) 116-122. (doi:10.1159/000192448)

Daly AF, Tichomirowa MA, Petrossians P, Heliövaara E, Jaffrain-Rea ML, Barlier A, Naves LA, Ebeling T, Karhu A, Raappana A et al. 2010 Clinical characteristics and therapeutic responses in patients with germ-line AIP mutations and pituitary adenomas: an International collaborative study. Journal of Clinical Endocrinology and Metabolism 95 E373-E383. (doi:10.1210/jc.20092556)

Dumitrescu CE \& Collins MT 2008 McCune-Albright syndrome. Orphanet Journal of Rare Diseases 312. (doi:10.1186/1750-1172-3-12)

Ezzat S, Asa SL, Couldwell WT, Barr CE, Dodge WE, Vance ML \& McCutcheon IE 2004 The prevalence of pituitary adenomas: a systematic review. Cancer 101 613-619. (doi:10.1002/cncr.20412)
Fernandez A, Karavitaki N \& Wass JA 2010 Prevalence of pituitary adenomas: a community-based, cross-sectional study in Banbury (Oxfordshire, UK). Clinical Endocrinology 72 377-382. (doi:10.1111/j.1365-2265.2009.03667.x)

Heliovaara E, Raitila A, Launonen V, Paetau A, Arola J, Lehtonen H, Sane T, Weil RJ, Vierimaa O, Salmela P et al. 2009 The expression of AIP-related molecules in elucidation of cellular pathways in pituitary adenomas. American Journal of Pathology 175 2501-2507. (doi:10. 2353/ajpath.2009.081131)

Jaffrain-Rea ML, Angelini M, Gargano D, Tichomirowa MA, Daly AF, Vanbellinghen JF, D'Innocenzo E, Barlier A, Giangaspero F, Esposito V et al. 2009 Expression of aryl hydrocarbon receptor (AHR) and AHR-interacting protein in pituitary adenomas: pathological and clinical implications. Endocrine-Related Cancer 16 1029-1043. (doi:10.1677/ERC-09-0094)

Kovacs K, Horvath E, Thorner MO \& Rogol AD 1984 Mammosomatotroph hyperplasia associated with acromegaly and hyperprolactinemia in a patient with the McCune-Albright syndrome. A histologic, immunocytologic and ultrastructural study of the surgically-removed adenohypophysis. Virchows Archiv. A, Pathological Anatomy and Histopathology 403 77-86. (doi:10.1007/ BF00689340)

Kristiansen G 2010 Manual microdissection. Methods in Molecular Biology 576 31-38. (doi:10.1007/978-1-59745545-9_2)

Leontiou CA, Gueorguiev M, van der Spuy J, Quinton R, Lolli F, Hassan S, Chahal HS, Igreja SC, Jordan S, Rowe J et al. 2008 The role of the aryl hydrocarbon receptorinteracting protein gene in familial and sporadic pituitary adenomas. Journal of Clinical Endocrinology and Metabolism 93 2390-2401. (doi:10.1210/jc.2007-2611)

Magri F, Villa C, Locatelli D, Scagnelli P, Lagonigro MS, Morbini P, Castellano M, Gabellieri E, Rotondi M, Solcia E et al. 2010 Prevalence of double pituitary adenomas in a surgical series: clinical, histological and genetic features. Journal of Endocrinological Investigation 33 325-331. (doi:10.3275/6716)

Osamura RY, Kajiya H, Takei M, Egashira N, Tobita M, Takekoshi S \& Teramoto A 2008 Pathology of the human pituitary adenomas. Histochemistry and Cell Biology 130 495-507. (doi:10.1007/s00418-008-0472-1)

Pack SD, Kirschner LS, Pak E, Zhuang Z, Carney JA \& Stratakis CA 2000 Genetic and histologic studies of somatomammotropic pituitary tumors in patients with the "complex of spotty skin pigmentation, myxomas, endocrine overactivity and schwannomas" (Carney complex). Journal of Clinical Endocrinology and Metabolism 85 3860-3865. (doi:10.1210/jc.85.10.3860)

Pellegata NS, Quintanilla-Martinez L, Siggelkow H, Samson E, Bink K, Hofler H, Fend F, Graw J \& Atkinson MJ 2006 Germ-line mutations in p27Kip1 cause a multiple endocrine neoplasia syndrome in rats and humans. PNAS 103 15558-15563. (doi:10.1073/ pnas.0603877103) 
Raitila A, Lehtonen HJ, Arola J, Heliövaara E, Ahlsten M, Georgitsi M, Jalanko A, Paetau A, Aaltonen LA \& Karhu A 2010 Mice with inactivation of aryl hydrocarbon receptor-interacting protein (Aip) display complete penetrance of pituitary adenomas with aberrant ARNT expression. American Journal of Pathology 177 1969-1976. (doi:10.2353/ajpath.2010.100138)

Scheithauer BW, Kovacs KT, Stefaneanu L, Horvath E, Kane LA, Young WF Jr, Lloyd RV, Randall RV \& Davis DH 1995 The pituitary in gigantism. Endocrine Pathology 6 173-187. (doi:10.1007/BF02739881)

Stratakis CA, Tichomirowa MA, Boikos S, Azevedo MF, Lodish M, Martari M, Verma S, Daly AF, Raygada M, Keil MF et al. 2010 The role of germline AIP, MEN1, PRKAR1A, CDKN1B and CDKN2C mutations in causing pituitary adenomas in a large cohort of children, adolescents, and patients with genetic syndromes. Clinical Genetics $\mathbf{7 8}$ 457-463. (doi:10.1111/j.1399-0004.2010.01406.x)

Trouillas J, Labat-Moleur F, Sturm N, Kujas M, Heymann MF, Figarella-Branger D, Patey M, Mazucca M, Decullier E, Verges B et al. 2008 Pituitary tumors and hyperplasia in multiple endocrine neoplasia type 1 syndrome
(MEN1): a case-control study in a series of 77 patients versus 2509 non-MEN1 patients. American Journal of Surgical Pathology 32 534-543. (doi:10.1097/PAS. Ob013e31815ade45)

Vierimaa O, Georgitsi M, Lehtonen R, Vahteristo P, Kokko A, Raitila A, Tuppurainen K, Ebeling TM, Salmela PI, Paschke R et al. 2006 Pituitary adenoma predisposition caused by germline mutations in the AIP gene. Science 312 1228-1230. (doi:10.1126/science.1126100)

Villa C, Magri F, Morbini P, Falchetti A, Scagnelli P, Lovati E, Locatelli D, Canevari FR, Necchi V, Gabellieri E et al. 2008 Silent familial isolated pituitary adenomas: histopathological and clinical case report. Endocrine Pathology 19 40-46. (doi:10.1007/ s12022-008-9018-2)

Received in final form 24 March 2011

Accepted 30 March 2011

Made available online as an Accepted Preprint 30 March 2011 